\title{
290 Surgical Procedures for Ulnar Nerve Entrapment at the Elbow: Physiopathology, Clinical Experience and Results
}

\author{
M. Artico $^{1}$, F. S. Pastore ${ }^{1}$, F. Nucci, and R. Giuffre ${ }^{2}$ \\ ${ }^{1}$ Department of Neurological Sciences, University of Rome "La Sapienza", Rome, Italy \\ ${ }^{2}$ Institute of Neurosurgery, University of Rome "Tor Vergata", Rome, Italy
}

\section{Summary}

Ulnar nerve entrapment at the elbow is an important and relatively frequent pathological condition that may be related to diffent causes depending on individual or external factors. The cause of the nerve lesion is also idiopathic in about one-quarter to one-third of cases. This variable aetiopathogenetic presentation has often suggested different diagnostic and clinical approaches and, moreover, various surgical procedures. We present our 8-years surgical experience with 290 cases of ulnar nerve entrapment at the elbow analysing the salient clinical features and the results of the surgical treatment in the light of the relevant literature available on this topic.

Keywords: Ulnar nerve; elbow; entrapment neuropathy, epitrochlear groove; surgical management; electromyography; tardy ulnar palsy.

\section{Introduction}

The entrapment of the ulnar nerve at the elbow results from different pathological conditions such as degenerative or inflammatory diseases, congenital defects, iatrogenic or occupational diseases, metabolic or nutritional disorders $[8,11,12,16,18,37,43,46,47$, 54]. The increased vulnerability to compression of the nerve trunk at this level is conditioned by its anatomical relationships $[3,5,7,10,13]$ : in fact, the nerve is running between the medial belly of the triceps muscle and humerus condyle. The aponeurosis, connecting to the intermuscular septum, and the muscle itself are closely following the nerve as far as it enters the trochlear groove, covered by a sheath of connective tissue extending to the two-folded belly of the flexor carpi ulnaris. Ulnar nerve compression may be related, besides external factors, to anatomical individual variations and it is a common cause of arm and hand pain, paraesthesias and weakness [7, 13, 14, 37]. A correct preoperative evaluation and careful planning of the surgical procedure are essential for a good therapeutic result. Our 8-years experience (1985-1992) with 290 surgically treated instances of ulnar nerve entrapment is reported and results compared with the relevant literature, focusing on the main clinical and therapeutic findings of this pathological condition.

\section{Patients and Methods}

236 patients with ulnar nerve entrapment at the elbow (140 males and 96 females) were observed from January 1985 and December 1992. In 54 patients bilateral ulnar nerve involvement was present (290 surgical procedures for ulnar nerve compression). Patients were between 17 and 69 years old with a mean age of 42.5 (median 45.5). History ranged from 1 to 7 years with an average lenght of 3.5 years. In $33 \%$ of cases the presence of local (fractures with deformities or dislocation, cubitus valgus, muscles anomalies, rheumatoid arthritis) or systemic (diabetes, alcohol abuse, polineuropathies) factors were diagnosed.

Subjective symptoms and neurological signs both contributed to the clinical picture. As far as these are concerned, we found paraesthesias in $93 \%$, motor weakness in $66 \%$, pain $44 \%$ of cases. Neurological examination revealed a sensory deficit in $80 \%$, a motor deficit in $75 \%$, and muscular loss in $66 \%$ of instances. A clinical grading of ulnar loss of function was devised, featuring three classes: 1) patients complaining of subjective disturbances but without neurological signs and showing only mild neurophysiological test (NPT) alterations (17\%); 2) patients with neurological signs and showing significative NPT pathological changes $(61 \%)$; 3 ) patients with neurological signs and serious NPT alterations (22\%). NPT alterations were considered the detection of signs of denervation, alteration of intention patterns and reduction of conduction velocities across elbow to less than $48 \mathrm{~m} / \mathrm{sec}$.

The following therapeutic clinically-related criteria were used to select the patient for the proper surgical treatment: a) for the patients with acute neuropathy conservative treatment was advised; b) a decompressive surgical procedure was performed in patients of groups 1 and 2, with an history of less than 12 months, if clinical examina- 
Table 1. 1985-1993: 290 Surgically Treated Cases (in 54 Cases Ulnar Nerve Entrapment was Bilateral)

\begin{tabular}{lllll}
\hline Three symptom classes (12 mths min.) & Subjective symptoms & Neurological examination & Surgical treatment & Follow up \\
\hline $\begin{array}{l}\text { I: Pat. with subj. dist. without neurol. } \\
\text { sympt. \& showing mild EMG alter- }\end{array}$ & paraesthesia $93 \%$ & sensory deficit $80 \%$ & decompr. $75 \mathrm{c}$. & excellent $58 \%$ \\
$\begin{array}{l}\text { ations only (17\%) } \\
\text { motor weakn. 66\% }\end{array}$ & $\begin{array}{l}\text { motor deficit } 45 \% \\
\text { muscular loss } 66 \%\end{array}$ & $\begin{array}{l}\text { superf. transp. 195 c. } \\
\text { deep transp. 20 c. }\end{array}$ uood 27\% \\
unchanged $15 \%$
\end{tabular}

tion disclosed an ulnar nerve entrapment syndrome, in spite of a wide trochlear groove; c) in patients bearing anomalies or muscular hypertrophy a deep transposition was the procedure of choice; d) a superficial transposition (subcutaneous) was preferred in the remaining cases. Since acute neuropathy cases were not included in the present report (no surgery), the decompression procedure was performed in $13 \%$ of patients, the superficial transposition in $80 \%$ and the deep transposition in $7 \%$ of instances.

The follow-up of patients, although ranging from 1 to 8 years, was considered at 1 year after surgery, to permit a more homogeneous evaluation of results and to overcome the effects of poor co-operation of patients requested to attend for check-ups over longer periods.

Table 1 summarizes surgical results of the whole series of patients. We registered no major surgical complication and few minor complications such as a hypertrophic scar (5 cases) with a poor cosmetic result and one short lasting superficial infection (successfully treated with systemic antibiotics).

\section{Results}

Between 1985 and 1993236 patients with ulnar nerve compression at the elbow were operated on at our Institution. Males prevailed in comparison to females (140 vs. 96) and age ranged between 17 and 69 years (mean 42.5; median 45.5). In 54 instances the entrapment syndrome was bilateral and surgical treatment was accomplished in two stages. Preoperative clinical evaluation of patients prompted us to devise a three classes classification according to subjective symptoms, objective signs and EMG findings, as above described. Distribution of patients in the three classes was as follows: 40 patients (17\%) in Class I, 144 patients $(61 \%)$ in Class II and 52 patients $(22 \%)$ in Class III (Table 1).

The most common subjective symptom was paraesthesia (93\%), followed by motor weakness $(66 \%)$ and pain $(40 \%)$. At neurological examination sensory deficit resulted in the most frequent finding $(80 \%)$, while muscular loss and motor deficit were less common (respectively accounting for $66 \%$ and $45 \%$ ). Surgical procedure consisted mainly of superficial (subcutaneous) transposition (195 nerves $-80 \%$ ), followed by decompression $(75$ nerves $-13 \%)$ and deep (intramuscular) transposition (20 nerves $-7 \%$ ). Follow-up ranged from 12 to 96 months, but our evaluation was confined to 1 year after surgery. After this interval 58\% of cases showed marked improvement of the neurological status with subjective normalization (excellent); $27 \%$ of cases revealed a fair improvement of the neurological symptoms with mild sensory subjective disturbances (good); $15 \%$ of cases remained unchanged. We did not register any further deterioration in the surgical cases.

\section{Discussion}

Both systemic and local affection may induce the onset of an ulnar nerve distress at the elbow: congenital anomalies (cubitus valgus, epithrocleoanconeus, thickening either of the triceps, medial belly, or of the aponeurosis of the deep flexor pronator), trauma (elbow luxations, distal humeral lesions), arthritis, tumoural lesions (ganglion cysts, lipomas), iatrogenic injuries (post-anaesthetic, haemorrhagic, due to wrong positioning during operations or in bedridden patients), nutritional or metabolic disorders (diabetes, alcoholic addiction, toxics exposure), occupational diseases (manufacturers, truck drivers, computer or desk employees) and rare illnesses (lepromatosis, biceps rupture) $[2,8,12,16,18,36,37,38$, $39,43,44,45,46,56,60]$. Individual anatomical variations of the nerve course and situation as well as the peculiar pathologic effect of the different aetio- 
logical factors, remarkably influence the degree of functional impairment [3, 7, 13, 27, 28, 29, 30, 54].

Though general principles seem to be lacking to enable the neurosurgeon to predict the degree of functional impairment induced by a compromised nerve situation, the factors involved in causing a theorical nerve trouble seem actually counterbalanced by some kind of neural (and/or biological) defense reaction [36]. The ability of the nerve structure to slide and the action of gliding surfaces also between the inner nerve fascicles must a role play $[3,10,14,36]$. That is to say that a compression neuropathy is almost never a simple compression neuropathy.

The compression will result in a functional problem if surrounding oedema, microstretching injuries, extraneural scarring, epineural fibrosis are serious enough to affect the intraneural microcirculation, the axonal transport of nutrients, the cell bodies and so on. These alterations will finally lead to demyelination, conducting problems and fiber degeneration $[11,14$, 17].

For the very high length/diameter ratio and the distance from the cell body, the peripheral nerve axons are strictly dependent on the neurovascular environment as far as metabolic and catabolic exigences are concerned.

The small epineural vessels divide in ascending and descending branches. This epineural network, after forming an anastomotic network in the subepineurium, further form a vascular plexus at the perineurium. The vascular plexus at the level of perineurium sends small end-arteries and capillaries within the fascicles to complete the deep vascular network $[17,52]$.

Endoneural microvessels feature big diameters, large intercapillary distances, and scarce perivascular smooth muscle. These anatomical grounds explain the poor autoregulation of endoneural vasculature, so that even small changes of nerve blood flow and perfusion pressure are not compensated [52].

Endoneural oedema, further enhancing vessel distance and determining vessel collapse, greatly affects the integrity of the blood-nerve interface $[42,51,36]$. In fact, since the perineurium is not permeable and endoneural capillaries are very selective in molecule filtration, the endoneural compartment results in being relatively isolated. Therefore, oedema increases endoneural hydrostatic pressure with endothelial hypoxia and consequent axonal damage [51, 58]. There is also experimental evidence that endoneural oedema is able to negatively influence axonal regeneration inducing fibroblastic invasion with intraneural scar formation [41].

The production of free radicals or of oxidated products of low density lipoproteins has been claimed to induce cytotoxicity and decrease of the antioxidative capacity $[1,9,31]$. Long peripheral axons, for their content of phospholipidic membranes are very sensitive to oxidative damage [23, 49].

Axoplasmic transport of molecules synthetised in the cell body, uses oxidative phosphorilation of the axonal mitochondria to produce high-energy phosphates. Segmental axonal ischaemia due to a mild decrease of blood flow implies a loss of energy for the transport as well as for the sodium-pump system. Cell membrane is also affected by this energetic default, with consequent loss of conduction and transmission by the axon. The segment of axon in which ischaemia is produced, for local anatomy and/or raised internal pressure, not only will give rise to vascular mechanisms, but will also change its own ionic content, with further changes in endoneural hydrostatic pressure $[4$, $50,51]$.

A correlation between symptoms and histological findings was often attempted aiming to establish objective criteria for surgical indications, prognosis and therapeutic result evaluation.

Tingling and paraesthesias were related to microcirculation dysfunction leading to hypoxia [36].

Intermittent oedema was claimed to cause intermittent symptoms, however permanent sensory and motor deficits should be interpreted as initial demyelination. Muscle wasting and loss of sensibility should, on the other hand, imply fiber degeneration [36].

Moreover, there is evidence suggesting that other factors play a determining role in the so called compression neuropathy. Nerve fascicle arrangement, anatomically classified as "simple" and "compound", may influence the compression tolerance as well as the distance of the entrapped branch from the main trunk [30]. A vascular mechanism or a compromised axonal transport may respectively be invoked.

Anatomical studies have also suggested that the nerve fibers from the terminal digital sensory branch and to the small muscles of the hand, at the elbow lie deeply in the nerve, adjacent to the bone where they could be more easily exposed to injuries [50, 51].

Similar aetiopathogenetic hypotheses could explain the "double crush" syndrome in which a cervical root compression would make a minor elbow pathology 
able to produce ulnar neuropathy $[11,13,37]$. The reported higher damage susceptibility of the three terminal digital sensory fascicles and fascicles to intrinsic hand muscles could be interpreted analogously.

For the correct diagnosis and treatment of ulnar nerve entrapment, a careful clinical and electrophysiological evaluation and a fair surgical planning are recommended. Options for the best treatment are conditioned by the ability to find a correspondence between the clinical picture and the anatomical situation, grouping the patients in homogeneous classes addressed to the surgical procedures. Preoperative grading of patients was introduced by McGowan in 1950 [38] and Osborne in 1966 [43], based respectively on ulnar motor impairment and and ulnar sensorymotor deficit progression. Our experience prompted us to rely on a syncretic three-class selection, based upon subjective, objective and electrophysiological criteria. Predisposing conditions such as alcoholism, diabetes, in addition to symptoms duration, are well known to compromise at different levels the vascular or the neurobiological condition of the compressed nerve $[6,17$, $18,24]$. The interpretation of the symptomatic compression neuropathy as a result of a series of multifactorial local and non local dysfunction mechanisms, represents a possible explanation of the fact that these patients have usually more than one complaint. Besides neurological examination ("en griffe" shaped hand, muscle hypotrophy, sensory disturbances and the presence of the sign of Froment,) EMG represents an invaluable diagnostic tool, supplying decisive informations about the conduction speed of the affected nerve and the site of compression, although the neurophysiological testing barely correlates with the clinical features [54]. One possible explanation is that conduction velocities are not sensitive to axonal loss as they are to demyelination [40]. However when clear dysfunction was detected, a pathological process was always identified at surgery and the role of EMG studies is still relevant in the differential diagnosis, e.g. with the thoracic outlet syndrome or Pancoast's tumour [17].

Tardy ulnar palsy (TUP) is the fourth most common entrapment neuropathy (after carpal tunnel, cervical rib compression and meralgia paraesthetica) [27].

The clinical features more commonly include paraesthesias and signs of sensory-motor involvement, while pain and relevant motor deficits are less represented [17]. We were able to detect systemic or local predisposing factors in $1 / 3$ of the reported cases. Fac- tors favourably influencing the outcome were: age less than 50 and a short clinical history, while a worse prognosis could be expected in patients with serious muscle hypotrophy, concurrent systemic diseases and a longer history. The typical patient is middle-aged, male (more frequent to trauma exposure), Tinel's sign positive and complaints of motor and sensory disturbances on the non-dominant side. These consist of paraesthesias of 4th and 5th fingers, pain on the ulnar side of the forearm, weakness in the ulnar muscles of the hand. TUP is mainly caused by trauma (15-47\%), sometimes not mentioned in the history [27, 28]. A childhood trauma is reported in $20 \%$ of the cases [27]. This frequently follows fractures if these are associated with cubitus valgus $[28,49]$. Other causes are arthritis (20-38\%) [12] and recurrent trauma (4\%) [44, 45, 47]. Although bilaterality of elbow neuropathy is sustained by some Authors [25], the EMG evidence without clinical symptoms does not justify any therapeutic procedure. In our series bilateral TUP was present in $18.6 \%$ of cases and no correlation with predisposing conditions or factors was found.

Plain X-ray films of the elbow may reveal degenerative bony changes, old fractures and increased valgus angulation [28, 53]. CT and MRI data are still anecdotal in the literature. In our experience, while MRI studies provide available information about aponeurotic and/or muscle abnormalities and lesions narrowing the cubital space, CT is more helpful in revealing bony changes (e.g. osteophytes) in the cubital tunnel.

Electromyography and conduction velocities studies often demonstrate denervation potentials in the flexor carpi ulnaris or in the abductor digiti minimi and slowing of motor (not frequently) and/or sensory nerve conduction $[6,20,48,54]$.

The differential diagnosis is based on clinical and neurophysiological criteria, expecially taking into account C8-T1 root involvement by cervical spondylosis or discopathy, thoracic outlet syndrome, Pancoast tumours [17].

Since widely accepted grading criteria for these patients are lacking, the therapeutic guidelines are still a matter of debate by various Authors. Moreover, controversies arise because the relevant literature consists of series of a single surgeon, invariably accustomed to a particular surgical technique (therefore surgical strategies are not the result of comparable criteria of patient selection).

In order to avoid these problems, we attempted to strictly define three supposedly homogeneous classes 
of patients, tailoring for each the therapeutic strategy and an appropriate surgical option. The surgical results at the 1-year follow-up are satisfactory. In fact, $85 \%$ of patients improved after surgery $(65 \%$ excellent and $20 \%$ good), whereas only $15 \%$ resulted in no change. Cases with particular features benefit from simple decompression (13\%) and from deep transposition $(7 \%)$, while the technique most frequently employed was the superficial transposition $(80 \%)$. Surgical approach appears to deserve little consideration to the specific cause. This reflects the lack of prospective randomized studies, performed using more than one procedure in the screening of the clinical material. Moreover, follow-up studies are usually too short for a pathological condition that often shows long lasting recovery and spontaneous healing. Therefore, the published studies are contradictory concerning the efficacy of the different surgical procedures and the rate of satisfactory results. The only conclusion is that the postoperative results reflect the preoperative status regardless of the surgical procedure $[5,6,19,28$, $32,55]$. General agreement is also registered concerning the conservative treatment of patients with intermittent symptoms and the worse prognosis of patients complaining of symptoms lasting more than one year or with muscle atrophy [5, 14, 15, 22, 34, 39].

The role of epicondylectomy, of transposition and of intramuscular relocation techniques is controversial $[21,26,33,35,59]$. Retro-epicondylar compression is claimed to be more frequent than cubital tunnel syndrome, but this opinion requires further confirmation $[7,57]$.

Transposition may be more effective than simple decompression in patients with a history longer than one year [14, 28, 34].

However, three months after surgery, conduction is still below normal in $30 \%$ of cases, often with residual symptoms and signs [20, 40]. Five months postoperatively action potentials may remain subnormal [20]. The widespread use of a rating system for the evaluation of results is greatly desirable and the Bishop's scale may represent a starting point [32]. Conduction studies are advisable in surgical patients, whether they have or have not improved after the procedure.

These remarks are essentially in agreement with those of the major series in the literature.

On the other hand, we must be able in the future to fruitfully compare data and conclusions drawn from very large series and different surgical experiences.
Eventually, the correlation between anatomo-clinical data and surgical strategy, in spite of the protean aetiopathogenesis of the syndrome, remains, in our opinion, the desirable solution to tailor the treatment to the requirements of the single case.

\section{References}

1. Alexander JJ, Graham DJ, Miguel R (1991) Oxygen radicals alter permeability and uptake by an endothelial-smooth muscle cell bilayer. J Surg Res 51: 361-367

2. Alvine FG, Schurrer ME (1987) Postoperative ulnar nerve palsy. J Bone Joint Surg 63A: 255-259

3. Apfelberg DB, Larson SJ (1973) Dynamic anatomy of the ulnar nerve at elbow. Plast Reconstr Surg 51: 76-81

4. Ask P, Levitan H, Robinson PJ, Rapoport SI (1983) Peripheral nerve as an osmometer: role of the perineurium in frog sciatic nerve. Am J Physiol 244: C75-C81

5. Assmus H (1984) Die operative Behandlung des KubitaltunnelSyndroms und der Ulnaris-Spaetparese durch einfach Dekompression. Bericht ueber 108 Faelle. Neurochirurgia 27: 181-185

6. Benoit BG, Preston DN, Atack DM, Da Silva VF (1987) Neurolysis combined with the application of a Silastic envelope for ulnar nerve entrapment at the Elbow. Neurosurgery 20: 594-598

7. Campbell WW, Pridgeon RM, Riaz G, Astruc J, Sahni KS (1991) Variations in anatomy of the ulnar nerve at the cubital tunnel: pitfalls in the diagnosis of ulnar neuropathy at the elbow. Muscle Nerve 14: 733-738

8. Carayon A (1971) Investigations on physiopathology of the nerve in leprosy. Int J Leprosy 81: 278-294

9. Cathcart MK, Morel DW, Chisolm III GM (1985) Monocytes and neutrophils oxidize low density lipoprotein making it cytotoxic: J Leukoc Biol 38: 341-350

10. Chan RC, Paine KW, Varughese G (1980) Ulnar nerve at the elbow: comparison of subcutaneous decompression and anterior transposition. Neurosurgery 7: 545-550

11. Dahlin LB, Lundborg G (1990) The neuron and its response to peripheral nerve compression. J Hand Surg 15B: 5-10

12. De Andrade JR, Casagrende PA (1965) Ulnar nerve entrapment in rheumatoid arthritis. Arthritis Rheuma 8: 294-301

13. Dellon AL (1986) Muscolotendinous variations about the medial humeral epicondyle. J Hand Surg 11B: 175-181

14. Dellon AL (1989) Review of treatment results for ulnar nerve entrapment at the elbow. J Hand Surg 14A: 688-700

15. Durandeau A, Chavoix JB, Geneste R (1987) A propos de 91 compressions du nerf cubital au niveau du coude. Rev Chir Orthop 73 [Suppl] II: 240-242

16. Ekerot L (1977) Post-anesthetic ulnar neuropathy at the elbow. Scand J Plast Reconstr Surg 11: 225-229

17. Eversmann WW Jr (1983) Compression and entrapment neuropathy of the upper extremity. J Hand Surg 8A: 759-766

18. Frazier DM, Campbell IW, Ewing DJ, Clark BF (1979) Mononeuropathy in diabetes mellitus. Diabetes 28: 96-101

19. Friedman RJ, Cochran TP (1986) Anterior transposition for advanced ulnar neuropathy at the elbow. Surg Neurol 25: 446448

20. Friedman RJ, Cochran TP (1987) A clinical and electrophysiological investigation of anterior transposition for ulnar neuropathy at the elbow. Arch Orthop Trauma Surg 106: $375-$ 380

21. Froimson AI, Anouchi YS, Seitz WH Jr, Winsberg DD (1991) Ulnar nerve decompression with medial epicondylectomy for 
neuropathy at the elbow. Clin Orthop Rel Research 265: 200206

22. Gabel GT, Amadio PC (1990) Reoperation for failed decompression of the ulnar nerve in the region of the elbow. J Bone Joint Surg 72A: 213-219

23. Gelman BB, Goodrum J, Bouldin TW (1991) Macrophage apolipoprotein synthesis and endoneurial distribution as a response to segmental demyelination. J Neuropathol Exp Neurol 50: $383-407$

24. Goldberg BJ, Light TR, Blair SJ (1989) Ulnar neuropathy at the elbow: results of medial epicondylectomy. J Hand Surg 14A: 182-188

25. Harmon RL (1991) Bilaterality of ulnar neuropathy at the elbow. Electromyogr Clin Neurophysiol 31: 195-198

26. Heithoff SJ, Millender LH, Nalebuff EA, Petruska AJ Jr (1990) Medial epicondylectomy for the treatment of the ulnar nerve compression at the elbow. J Hand Surg 15A: 22-29

27. Hirsh LF, Thanki A (1985) Ulnar nerve entrapment at the elbow. Tailoring the treatment to the cause. Postgrad Med 77: 211-215

28. Hoellerhage HG, Stolke D (1985) Ergebnisse der volaren Transposition des Nervus ulnaris bei Sulcus-ulnaris Syndrom. Neurochirurgia 28: 64-67

29. Inserra S, Spinner M (1986) An anatomic factor significant in transposition of the ulnar nerve. J Hand Surg 11A: 80-82

30. Jabaley ME, Wallace WH, Heckler FR (1980) Internal topography of major nerves of the forearm and hand: a current view. J Hand Surg 5: 1-18

31. Kihara M, Schmelzer JD, Poduslo JF, Curran GL, Nickander KK, Low PA (1991) Aminoguanidine effects on nerve blood flow, vascular permeability, electrophysiology and oxygen free radicals. Proc Nat Acad Sci 88: 6107-6111

32. Kleinmann WB, Bishop AT (1989) Anterior intramuscular transposition of the ulnar nerve. J Hand Surg 14A: 972-979

33. Laha RK, Panchal PD (1979) Surgical treatment of ulnar neuropathy. Surg Neurol 11: 393-398

34. LeRoux PD, Ensign TD, Burchiel KJ (1990) Surgical decompression without transposition for ulnar neuropathy: factors determining outcome. Neurosurgery 27: 709-714

35. Lugnegard H, Waldheim G, Wenberg G (1977) Operative treatment of ulnar nerve neuropathy in the elbow region. Acta Orthop Scand 48: 168-176

36. Lundborg G (1992) Surgical treatment for ulnar nerve entrapment at the elbow (editorial). J Hand Surg 17B: 245-247

37. Mackinnon SE, Lee Dellon A (1988) Surgery of the peripheral nerve. Georg Thieme Verlag, Stuttgart New York, pp 217273

38. McGowan AJ (1950) The results of transposition of the ulnar nerve for traumatic ulnar neuritis. J Bone Joint Surg 32B: 293301

39. Manske PR, Johnston R, Pruitt DL, Strecker WB (1992) Ulnar nerve decompression at the cubital tunnel Clin Orthop Rel Research 274: 231-237

40. Nathan PA, Myers LD, Keniston RC, Meadows KD (1992) Simple decompression of the ulnar nerve: an alternative to anterior transposition. J Hand Surg 17B: 251-254
41. Nitz AJ, Dobner JJ, Matulionis DH (1989) Structural assessment of rat sciatic nerve following tourniquet compression and vascular manipulation. Anatomical Record 225: 67-76

42. Olsson Y (1987) Vascular permeability in the peripheral nervous system. In: Dyck PJ, Thomas PK, Lambert EH, Bunge R (eds) Peripheral neuropathy, vol. 1, 2nd edition. Saunders, Philadelphia

43. Osborne G (1966) The elbow and forearm. In: Rob C, Smith R (eds) Clinical surgery. Butterworths, London, pp 417-454

44. Platt H (1926) The pathogenesis and treatment of traumatic neuritis of the ulnar nerve in the post-condylar groove. Br J Surg 13: 409-431

45. Platt H (1928) On the peripheral nerve complications of certain fractures. Surg Gynecol Obstet 47: 822-825

46. Poppi M, Staffa G, Martinelli P, Fabrizi AP, Giuliani G (1991) Neuropathy caused by spontaneous intraneural hemorrhage: case report. Neurosurgery 28: 292-295

47. Richards RL (1945) Traumatic ulnar neuritis: the results of anterior transposition of the ulnar nerve. Edinb Med J 52: 14-21

48. Robinson D, Aghasi MK, Halperin N (1992) Medial epicondylectomy in cubital tunnel syndrome: an electrodiagnostic study. J Hand Surg 17B: 255-256

49. Rothe T, Mueller HW (1991) Uptake of endoneurial lipoprotein into Schwann Cells and sensory neurons is mediated by low density lipoprotein receptors and stimulated after axonal injury. J Neurochem 57: 2016-2025

50. Rydevik B, Brown MD, Lundborg G (1984) Pathoanatomy and pathophysiology of nerve root compression. Spine 9: 7-15

51. Rydevik B (1992) The effects of compression on the physiology of nerve roots. Journal of Manip Physiol Thera 15: 62-66

52. Smith JW (1966) Factors influencing nerve repair. II. Collateral circulation of the peripheral nerves. Arch Surg 93: 433-437

53. St. John JN, Palmaz JC (1986) The cubital tunnel in ulnar entrapment neuropathy. Radiology 158: 119-123

54. Stewart JD (1987) The variable clinical manifestations of ulnar neuropathies at the elbow. J Neurol Neurosurg Psychiatry 50: 252-258

55. Stuffer M, Jungwirth W, Hussl H, Schmutzhardt E (1991) Subcutaneous or submuscular anterior transposition of the ulnar nerve? J Hand Surg 17B: 248-250

56. Vanderpool DW, Chalmers J, Lamb DW, Whitstson TB (1968) Peripheral compression lesions of the ulnar nerve. J Bone Joint Surg 50B: 792-802

57. Wadsworth TG, Williams RM (1977) Cubital tunnel external compression syndrome. Nurs Times 73: 1357-1359

58. Werner CO, Ohlin P, Elmqvist D (1985) Pressures recorded in ulnar neuropathy. Acta Orthop Scand 56: 404-406

59. Wilson DH, Kraut R (1973) Surgery of ulnar neuropathy at the elbow in sixteen cases treated by decompression without transposition. J Neurosurg 38: 780-785

60. Woltman HW (1930) Pressure as a factor in the development of neuritis of the ulnar and common peroneal nerves in bedridden patients. Am J Med Sci 179: 528-532

Correspondence: Marco Artico M.D., Department of Neurological Sciences, University of Rome "La Sapienza”, Rome, Italy. 